\title{
Idealismo Realista ou Realismo Idealista: Hegel \& Marx
}

\author{
Realistic Idealism or Idealist Realism: Hegel \& Marx
}

Agemir Bavaresco*

\begin{abstract}
Resumo: O tema do idealismo e realismo é abordado por Hegel e Marx de um modo específico. De um lado, Hegel entende que toda a verdadeira filosofia é um idealismo. De outro, Marx defende que o verdadeiro pensamento inicia com o realismo. Nós entendemos que as abordagens não são excludentes, pois, trata-se de pontos de partida diferentes. Os diagnósticos têm na contradição o motor da história; e na dialética o método de descrever e analisar o real. A partir das categorias da finitude e infinitude de Hegel e da categoria do fetichismo de Marx estabelecemos aproximações e diferenças entre os dois autores.
\end{abstract}

Palavras-Chaves: Finitude. Infinitude. Fetichismo. Contradição.

\begin{abstract}
The theme of idealism and realism is approached by Hegel and Marx in a specific way. On the one hand, Hegel understands that all true philosophy is an idealism. On the other, Marx argues that true thinking begins with realism. We understand that approaches are not mutually exclusive, because they are different starting points. Diagnoses have in contradiction the motor of history; and in dialectics the method of describing and analyzing the real. From the categories of finitude and infinity of Hegel and the category of Marx's fetishism we establish approximations and differences between the two authors.
\end{abstract}

Keywords: Finitude. Infinity. Fetishism. Contradiction.

\section{Introdução ${ }^{1}$}

Há uma contradição entre infinitude e finitude, que em Hegel recebe sua elaboração na forma de um idealismo realista, enquanto Marx a elabora como um realismo idealista ou racional. Para Hegel, toda a filosofia é um idealismo pois a finitude alcança a infinitude na mediação da ideia, ou seja, o finito se torna infinito através de um processo de

\footnotetext{
*Professor de Filosofia/PUCRS. < abavaresco@pucrs.br>

${ }^{1}$ Este texto foi publicado como capítulo do e-book. In: Leituras da Lógica de Hegel. Agemir Bavaresco; José Pinheiro Pertille; Marloren Lopes Miranda; Jair Tauchen (Orgs.). Porto Alegre, RS: Editora Fi, 2017, p. $35-58$.
} 
suprassunção que o torna conforme ao seu conceito. Para Marx, a filosofia do fetichismo da mercadoria explicita a finitude dos objetos produzidos pelo trabalho humano. Uma mercadoria finita, produto da mão humana, torna-se, por assim dizer, um fetiche infinito ao ingressar na rede das mercadorias. O realismo racional de Marx explicita em $O$ Capital que o fetiche da infinitude da mercadoria é finito, ou seja, demonstra a finitude da mercadoria. Em que sentido uma mercadoria, que é finita por definição, torna-se infinita ao inserir-se numa rede de mercadorias, quer dizer, no mercado? De que tipo de infinitude se trata? Por que essa infinitude tem um caráter de fetiche da mercadoria? O Capital descreve a idealidade do mundo das mercadorias que se tornam fetiches infinitos na sociedade capitalista, porém, Marx prova sua finitude, na medida em que apresenta sua articulação interna e os mecanismos de produção e circulação das mercadorias. Apresentamos, em primeiro lugar, o idealismo da infinitude em Hegel, e, depois, o idealismo da mercadoria como fetiche e a racionalidade da finitude da mercadoria em Marx. ${ }^{2}$

\section{1 - Idealismo da Infinitude hegeliana}

O idealismo de Hegel afirma que tudo está suprassumido no pensar, inclusive o próprio sujeito pensante. Não apenas o finito é ideal, mas também o ser para si é ideal, no qual o finito é ideal ou está suprassumido. Tudo está no pensar. O ser para si é um ser que apenas pensa a si mesmo. ${ }^{3}$ O ser para si puro é o ser que apenas é como ideal, como suprassumido em si mesmo. Não há nada real fora do pensar. O real deve ser, portanto, reconstruído, ou se quisermos conquistado a partir do pensar. O idealismo de Hegel é para Marx um niilismo consumado, como Jacobi já acusava o

\footnotetext{
${ }^{2}$ Registramos nossos agradecimentos aos colegas Christian Iber e Federico Orsini pelos comentários e observações feitas sobre o texto.

${ }^{3}$ Federico Orsini (2017) faz o seguinte esclarecimento a respeito do ser para si como pensamento de si mesmo: Do ponto de vista da Lógica, todas as formas do ser pensam a si mesmas, porque a Lógica é pensamento conceituante de pensamentos (as categorias). O que caracteriza o "ser para si" na Lógica é a suprassunção da relação de alteridade entre ser finito e ser infinito. No âmbito da filosofia como sistema (Lógica e filosofia real), pode-se dizer que "ser para si" é o ponto de vista do espírito, especificamente, do espírito consciente de si, que traz à tona as categorias que atuam de modo inconsciente na natureza. Nesse sentido, o espírito é ser que pensa a si mesmo, ou seja, reflete, enquanto a natureza é ser que ainda não reflete sobre seu agir. Mas, do ponto de vista da Lógica, o "ser" que age na natureza e no espírito é a Ideia, não apenas o ser que constitui o objeto da Doutrina do Ser.
} 
idealismo transcendental de Fichte de ser um niilismo. Ao contrário, Marx pretende manter a natureza não eliminável do finito, conforme afirma Iber (2013).

O idealismo de Hegel é também um realismo, mas um realismo a partir do idealismo, ou seja, um idealismo absoluto. Parece-me, diz Iber, que o materialismo de Marx não é simplesmente uma inversão do idealismo. Marx defende, também, uma unidade do realismo e do idealismo. Talvez se possa dizer, um realismo que contém em si a dimensão idealista, um materialismo racional. Nesse caso, o que é um materialismo racional? A grande questão é, segundo Iber, como se pode relacionar a discussão sobre o idealismo e realismo de Hegel e Marx com a crítica de Marx ao fetichismo dos objetos econômicos no capitalismo? Para elucidar esse problema reconstruímos a Observação 2, sobre o Idealismo, na segunda edição da Doutrina do Ser de Hegel (2016, p. 160 162).

\section{1 - Estrutura do texto: O idealismo}

O texto é composto de dois parágrafos que se localiza na $1^{\mathrm{a}}$ seção, no $2^{\circ}$ capítulo: $\mathrm{O}$ ser aí, do item C: A infinitude. O idealismo pode ter três expressões, segundo Hegel, o idealismo na filosofia, na religião e como espírito subjetivo.

$1^{\circ}$ parágrafo, p. 160 - 161: A filosofia é um idealismo

a) Finito e ideal: o idealismo tem sua constituição nesta afirmação: "O finito é ideal”. Em outras palavras isto significa que "o finito não é um ente verdadeiro". Então, "a filosofia é essencialmente idealismo”. Este é o princípio da filosofia e ela precisa verificar em que medida ele está efetivado.

b) Idealismo X realismo: a oposição entre filosofia idealista ou realista não tem importância. A filosofia não pode atribuir a um ser aí imediato a verdade, pois ele precisa ser elevado ao seu ideal. Os princípios da filosofia antiga (água, átomos) ou moderna "são pensamentos, universais, ideais" e não coisas e/ou algo sensível que podem ser encontrados imediatamente. c) Coisas singulares e ideias: as coisas singulares e sensíveis na medida em que são postas na sua idealidade precisam ser suprassumidas conforme o seu princípio ou conceito. A teoria da infinitude mostrou que o ideal é o 
concreto verdadeiro, porém, ele passa por um processo de idealização através de seus momentos suprassumidos na ideia.

$\mathbf{2}^{\mathbf{0}}$ parágrafo, p.16o - 161: Idealismo subjetivo

a) Ideal e representação: Hegel afirma que o uso do termo 'ideal' se refere ao nível da representação e da imaginação.

b) Idealismo subjetivo: o Eu tem o ser aí real, o ser externo de modo ideal na consciência, sob a forma da representação, isto é, um conteúdo de um sujeito.

c) Idealismo sistemático da subjetividade: este idealismo afirma a subjetividade como sendo a única forma verdadeira em oposição a forma objetiva ou a realidade do ser aí externo. Hegel afirma que este idealismo é formal, pois ele não leva em consideração o conteúdo do ato de representar. Isto reduz o seu conteúdo à finitude.

d) Subjetividade $X$ objetividade: esta oposição da forma conduz à finitude. Porém, o conteúdo como é assumido na sensação, intuição, representação, contém as finitudes que ainda não foram eliminadas. A oposição na forma subjetividade e objetividade exclui seu conteúdo e com isso permanece na finitude.

\section{2 - Idealismo da infinitude}

Para Hegel a filosofia é um idealismo na medida em que ela precisa reconhecer que o finito em si não é o verdadeiro, mas precisa conformar-se à ideia. Nesse sentido, o idealismo hegeliano é próximo ao de Platão, porque o finito não pode ser absolutizado, mas precisa de mediação para tornar-se outro, isto é, infinito. Em outras palavras o finito não contém apenas a realidade, mas a idealidade, no sentido, de que "ele não tem sua verdade em seu subsistir por si, mas no interior do infinito em que ele mesmo se suprassume. O finito é uma determinação diferente, mas não independente, do infinito" (ORSINI, 2017, p. 3). Por isso Hegel, critica tanto a filosofia idealista moderna representada por Kant e Fichte, como a filosofia realista em Jacobi. O ideal é o concreto que engloba em si os momentos do finito e do mau infinito incluídos no todo.

O idealismo na filosofia através da Lógica hegeliana supera o dualismo moderno entre ontologia e epistemologia. Kant com seu idealismo subjetivo e formal separa o ser do pensar. Para Hegel o ser e o 
pensar estão unidos na idealidade do finito. Isto não significa que o não ser do finito implique que as coisas não existam. O capítulo sobre o ser aí explicitou as estruturas lógicas de todas as coisas finitas. Assim, nas demais partes da Lógica, a finitude - que é a estrutura lógica de qualquer coisa finita - terá novas determinações e novas categorias: existência, fenômeno, contingência, objetividade.

O problema da separação entre ontologia e epistemologia é resolvido por Hegel ao elaborar um modelo que não fica mais dependente da pressuposição de que o pensamento está preso à consciência ou a um "eu penso". Isto não significa eliminar o problema do acesso mental ao mundo empírico através da consciência ou das ciências finitas, porém, isto já foi resolvido com a Fenomenologia.

A filosofia especulativa hegeliana não aceita como um pressuposto autoevidente que as coisas finitas como objetos estão desde sempre contrapostas a nós, obrigando-nos a atravessar a distância que nos separa daquilo que eles são em si. "O filósofo especulativo compreende que as coisas são objetos reais, independentes da 'mente', cuja estrutura ontológica é idêntica ao pensamento objetivo de 'ser algo', 'ser finito' e 'ser espaço-temporal’” (ORSINI, 2017, p. 4). Não há necessidade de ter acesso às coisas, diz Orsini, para descobrir suas estruturas ontológicas, basta apenas tornar explícitas as estruturas que estão implícitas no pensamento do ser puro. De fato, a "descoberta" das categorias pressupõe que haja um intercâmbio entre sujeito e objeto, consciência e mundo. Mas o ponto é que esse pressuposto genético da consciência finita não pode ser absolutizado, tornando-se o ponto de vista que rege a Lógica.

O estudo da Lógica tem certamente como suas pré-condições o surgimento da consciência e sua abertura constitutiva ao mundo efetivo, mas, uma vez que o sujeito finito resolve considerar as estruturas do mundo efetivo, as ditas pré-condições precisam ser suspendidas e progressivamente reconstruídas por meio da Lógica. Por causa disso, elas não estabelecem o fundamento determinante da verdade das categorias que a Lógica vem apresentando. Em outras palavras, as pré-condições genéticas do estudo da Lógica não são "condições de possibilidade" do conteúdo da Lógica, afirma Orsini.

O pensamento não está mais preso à exterioridade da separação entre forma e conteúdo. Hegel abandonou esta pressuposição de que as coisas se contrapõem ao pensamento; isto enreda o pensamento aos 
problemas tradicionais epistemológicos do 'acesso' ao real; ao contrário esses problemas recebem uma solução definitiva na "Lógica ontológica de Hegel” (ORSINI, 2017, p. 4).

\section{2 - Fetichismo da mercadoria em Marx: Da Infinitude à Finitude}

Na teoria do fetichismo da mercadoria, Marx apresenta como emerge o aparecimento da mercadoria. Ou seja, o fetichismo é uma forma de aparecimento da mercadoria que gera simultaneamente uma aparência. Ele mostra que a mercadoria, o dinheiro e o capital apresentam relações sociais entre pessoas que se realizam por meio de coisas. Trata-se de relações sociais estabelecidas entre objetos naturais e objetos produzidos. Elas geram a aparência que esses objetos são o fundamento das relações. Esse fenômeno é mediado objetivamente, ou seja, as relações estão objetivamente mediadas. Por isso surge a objetivação das relações sociais, isto é, relações de dominação social aparecem como obrigações objetivas. A tese de Marx em síntese é a seguinte: as relações sociais são relações de dominação que geram o aparecimento das coisas que dominam as pessoas. Ou seja, a mediação objetiva da dominação social pela mercadoria/dinheiro é um aparecimento objetivo. E as relações do modo de produção capitalista são, portanto, objetivadas ou coisificadas (ver Iber, 2013).

2.1 - Estrutura do texto: O caráter fetichista da mercadoria e seu segredo ${ }^{4}$

Aqui é decisiva uma distinção conceitual, para a qual chamou a atenção o estudioso italiano de Marx, Riccardo Bellofiore, entre "caráter de fetiche" (Fetischcharakter) da mercadoria e "fetichismo" (Fetischismus). O caráter de fetiche da mercadoria é a natureza objetiva, reificada e alienada da realidade da sociedade capitalista. O "caráter de fetiche" é o aparecimento do capitalismo, uma "Erscheinung" de sua essência, que é simultaneamente lógica e histórica.

\footnotetext{
${ }^{4}$ O filósofo francês Étienne Balibar que foi aluno de Louis Althusser do qual recebeu influência na leitura das obras de Marx, coordenou um seminário em homenagem aos 150 anos da publicação de $\mathrm{O}$ Capital, vol. I, em Londres junto à Kingston University, no "Centre for Research in Modern European Philosophy” (CRMP), de janeiro a março de 2017. Nós participamos deste seminário e, por isso, algumas das ideias, aqui apresentadas, são o resultado dos debates instigantes de tal curso.
} 
Ao contrário, o "fetichismo" diz respeito à possível atitude mental dos agentes envolvidos na sociedade capitalista. Fetichismo é a atribuição de propriedades sociais às coisas como se fossem propriedades naturais das próprias coisas. O "como se" aponta que o fetichismo é uma aparência enganosa, um "Schein” que esconde a essência social das propriedades das mercadorias.

Porém, Bellofiore destaca que a aparência é enganosa, apenas se a troca de propriedades sociais por propriedades naturais pretende colocar-se fora da relação social do capital ou naturalizar as relações capitalistas, considerando-as como formas universais (iguais em todos os tempos) da sociedade. Dentro da realidade capitalista, as propriedades sociais tendem a tornar-se efetivamente propriedades das coisas. Em outras palavras, o fetichismo é 'objetivo' (ou seja, impõe-se por trás das costas dos agentes sociais), porque é induzido pelo próprio "caráter de fetiche" das mercadorias (BELLOFIORE, 2014, pp. 164-188).

Balibar propôs uma leitura ontoepistemológica do item 4. O caráter fetichista da mercadoria e seu segredo, do Capítulo 1 - A mercadoria, da seção I. Mercadoria e dinheiro. O ser da essência do capital aparece num modelo ontológico de estrutura de relações sociais. Há uma inversão que ocorre entre a intersubjetividade e a interobjetividade, isto é, na intersubjetividade temos diferentes seres humanos em trabalho social em que a dimensão comum articula uma comunidade de relações. Enquanto que na interobjetividade social a relação dá-se entre o mercado e a circulação de objetos. Há uma inversão do polo intersubjetivo para o interobjetivo, pois passa-se de relações comunitárias entre sujeitos para relações de inversão do real em que a relação se dá entre indivíduos isolados como propriedade privada (Ver Marx, 2013, §§ 3 e 4, p. 147).

Apresentamos a seguir a estruturação do texto marxiano que para melhor compreensão o dividimos em vinte e dois parágrafos.

$1^{\circ}$ parágrafo, p. 146: Aparência da mercadoria

- A mercadoria aparenta ser imediatamente algo óbvio, porém, é uma coisa complexa de sutilezas metafísico-teológicas.

- Propriedades da mercadoria: Ela é o produto do trabalho humano para satisfazer as necessidades humanas, ou seja, trata-se de um valor de uso.

- O ser humano muda as formas da matéria natural segundo o que lhe é útil. A mesa continua a ser madeira, porém, quando emerge como 
mercadoria, ela se transforma como uma coisa que transcende os sentidos: uma “coisa sensível-suprassensível” (§ 1, p. 146).

$\mathbf{2}^{\circ}$ parágrafo, p. 146-147: Mercadoria é o produto do trabalho

- O caráter místico da mercadoria não decorre da natureza da determinação do valor e nem de seu valor de uso.

1) Os tipos de trabalhos úteis são um fato fisiológico ou funções do organismo humano.

2) A determinação quantitativa do valor é sua duração ou quantidade de trabalho para produzir os meios de subsistência. A qualidade do trabalho é diferente de sua quantidade.

3) Quando as pessoas trabalham umas para as outras, o trabalho assume uma forma social.

\section{$3^{\circ}$ parágrafo, p. 147: Enigma da mercadoria}

- O enigma da mercadoria surge da própria forma da mercadoria assim construída:

- A medida da força humana de trabalho é a quantidade de trabalho transferido para os produtos, isto é, as mercadorias, que expressam a igualdade dos trabalhos materializada na igual objetividade de valor dos produtos do trabalho.

- As relações entre produtores aparecem sob a forma de uma relação social entre os produtos do trabalho.

$4^{\circ}$ parágrafo, p. 147-148: Fetichismo ou a autonomia do mundo das mercadorias

- A forma da mercadoria é caracterizada por Marx como "misteriosa" e com a analogia do "nebuloso mundo da religião".

- A mercadoria reflete duas dimensões: (i) reflete o trabalho social objetivo dos trabalhadores; (ii) reflete a relação social dos produtores e a soma total do trabalho, ou seja, a relação social entre os objetos. Essa relação existe separada e fora dos produtores. Temos aqui uma substituição ou inversão entre as relações sociais do trabalho e a relação dos objetos, de acordo com Marx, "os produtos do trabalho se tornam mercadorias, coisas sensíveis e, ao mesmo tempo, suprassensíveis ou sociais" (ver p. 147). As relações sociais entre os seres humanos nos seus trabalhos são mediadas pelas 
relações entre os seus objetos produzidos: as mercadorias. As relações pessoais são mediadas objetivamente através das mercadorias.

- O conhecimento humano e a mercadoria: O processo de conhecimento é a relação entre objetividade e subjetividade. Marx compara como as coisas naturais se refletem na percepção sensível e como os produtos do trabalho enquanto mercadorias aparecem na consciência do ser humano.

- A analogia com o mundo nebuloso da religião: Os produtos do cérebro humano aparecem como figuras autônomas no mundo da religião. $\mathrm{O}$ mesmo processo ocorre no mundo das mercadorias: Marx afirma: "a isso eu chamo de fetichismo, que se cola aos produtos do trabalho tão logo eles são produzidos como mercadorias e que, por isso, é inseparável da produção de mercadorias" (ver p. 148).

\section{$5^{\circ}$ parágrafo, p. 148: O fetichismo e a sociedade capitalista}

- O fenômeno do fetichismo do mundo das mercadorias surge na sociedade capitalista ou na relação de trabalho capitalista.

\section{$6^{\circ}$ parágrafo, p. 148: Mercadorias e relações reificadas}

- Objetos de utilidade, mercadorias e produtos do trabalho: os objetos de utilidade se tornam mercadorias porque são produtos do trabalho de indivíduos privados. O trabalho de todos os indivíduos forma a totalidade do trabalho da sociedade.

- Trabalho privado, mediação e produtos de intercâmbio: a característica social específica do trabalho privado aparece apenas na troca dos produtos pelos produtores. O trabalho do indivíduo particular aparece no ato de troca entre produtores, mediado através dos seus produtos.

- Pessoas, coisas e relações sociais reificadas: a relação social entre o trabalho privado não aparece como relação social direta, mas sim como relações sociais reificadas, isto é, "entre pessoas e relações sociais entre coisas” (§ 6, p. 148).

\section{$7^{\mathbf{0}}$ parágrafo, p. 148: A medida comum - Trabalho abstrato}

- O produto do trabalho torna-se uma objetividade pela troca, o qual adquire a objetividade social uniforme como valor. $\mathrm{O}$ trabalho do produtor individual adquire o caráter social: a) Por um lado, o tipo útil de trabalho satisfaz uma necessidade social no ramo da divisão social do trabalho; b) Por outro lado, todo tipo particular de trabalho privado útil pode ser 
trocado com todos os outros tipos de trabalho privado útil. Ou seja, os trabalhos particulares satisfazem uma necessidade social, apenas se eles são trocáveis com outros tipos de trabalho que tenham o mesmo valor.

- A medida da troca é a igualdade entre diferentes tipos de trabalho. A única característica que eles têm em comum é a "força humana de trabalho, como trabalho humano abstrato" (ver p. 149).

- O caráter socialmente útil do trabalho privado é refletido na forma em que o produto do trabalho deve ser útil para outros. O caráter social da igualdade dos vários tipos de trabalho se reflete na forma do caráter de valor comum. Essa qualidade comum como valor é transferida em coisas diferentes como produtos do trabalho.

\section{$8^{\circ}$ parágrafo, p. 149: Valor e Trabalho}

1) A troca de mercadoria tem sua equivalência no trabalho humano homogêneo, ou seja, valor. Os seres humanos estão inconscientes dessa realidade, porque o valor transforma todos os produtos do trabalho como hieróglifos sociais. Eles tentam decifrar o segredo de seu próprio produto social.

2) O valor como o trabalho humano gasto para produzir as mercadorias marca o modo de produção capitalista.

$9^{\circ}$ parágrafo, p. 9, p. 149 - 150: Grandeza do valor pelo tempo de trabalho - um segredo

1) Em que proporções os produtos podem ser trocados? O valor dos produtos é estabelecido pela magnitude do valor. A magnitude varia de forma contínua, independentemente, da vontade dos trocadores. "Seu próprio movimento social possui, para eles, a forma de um movimento de coisas, sob cujo controle se encontram, em vez de eles as controlarem” (p. 150).

2) Os diferentes tipos de trabalho privado são reduzidos às proporções quantitativas, isto é, "o tempo de trabalho socialmente necessário à sua produção se impõe", e "a determinação da grandeza de valor por meio do tempo de trabalho é, portanto, um segredo que se esconde sob os movimentos manifestos dos valores relativos das mercadorias" (p. 150).

$1^{\circ}$ parágrafo, p. 150: Modo de apresentação e forma de Dinheiro 
1) A reflexão sobre o modo de apresentação do capitalismo: A análise científica sobre as formas da vida humana segue o oposto do movimento real ou histórico. As mercadorias e a sua circulação estão historicamente prontas: A análise dos preços das mercadorias - determinação da magnitude do valor - é a expressão comum de todas as mercadorias em dinheiro. Agora, a reflexão começa "após a festa" (post festum), afirma Marx.

2) Forma de dinheiro ou forma equivalente: esta forma final do mundo das mercadorias, a forma de dinheiro, esconde o aspecto social do trabalho privado e as relações sociais entre os trabalhadores. Portanto, essas relações aparecem como relações entre objetos materiais. O dinheiro é a encarnação universal do trabalho humano abstrato: "É justamente essa forma acabada - a forma-dinheiro - do mundo das mercadorias que vela materialmente em vez de revelar, o caráter social dos trabalhos privados e, com isso, as relações sociais entre os trabalhadores privados” (§ 10, p. 150). Quando os produtores de casacos trazem essas mercadorias em relação ao linho, ou com o ouro ou a prata que é o equivalente universal, a relação entre o trabalho privado e o trabalho social da sociedade aparece como forma de dinheiro.

11 $^{\circ}$ parágrafo, p. 151: Categorias econômicas e produção de mercadorias 1) As categorias da economia burguesa consistem nessas formas: as formas de pensamento que validam as relações de produção ou o modo de produção social historicamente determinado, isto é, a produção de mercadorias. As categorias econômicas são, portanto, formas de pensamento objetivas e não meras projeções subjetivas da consciência.

2) O misticismo do mundo das mercadorias e as mágicas dos produtos do trabalho com base na produção de mercadorias desaparece se nos reportarmos a outras formas de produção, em que os produtos não tem o caráter de mercadorias.

$12^{\circ}$ parágrafo, p. 151-152: Robinson Crusoe e valor

1) Marx compara a economia política a Robinson Crusoe em sua ilha enquanto executa trabalhos úteis, diferentes modos de trabalho humano e o tempo de trabalho que as quantidades de produtos custaram em média. 2) As relações entre Robinson Crusoe e os objetos contêm todos os determinantes essenciais do valor, mas não o de produção de mercadorias. 
$13^{\circ}$ parágrafo, p. 152: Relações sociais de dependência pessoal

1) O romance de Robinson Crusoe é diferente da Europa medieval. Aqui temos relações de dependência pessoal (servos e senhores). As transações da sociedade como serviços são formas de pagamento. A corveia pode ser medida pelo tempo, assim como o trabalho que produz mercadorias, mas a medida gasta a serviço de seu senhor é uma quantidade de sua própria força de trabalho pessoal.

2) Nesta sociedade, todas as relações sociais aparecem como relações pessoais e não são disfarçadas como relações sociais entre as coisas e os produtos do trabalho.

\section{$14^{\circ}$ parágrafo, p. 152-153: Trabalho comum X Mercadorias}

1) O trabalho em comum encontra-se na indústria rural patriarcal de uma família camponesa, que produz milho, gado, linho etc. para uso próprio. Estas coisas defrontam-se com a família como muitos produtos de seu trabalho comum, mas eles não se defrontam como mercadorias.

2) A força de trabalho é medida pelo tempo de trabalho, que é regulada por diferenças de sexo e idade, bem como por variações sazonais nas condições naturais do trabalho como característica social do próprio trabalho que atuam como instrumentos da força de trabalho conjunto da família.

$1^{\circ}$ parágrafo, p. 153: Produto individual (R. Crusoe) e social (Associação) Marx toma um exemplo de uma associação de pessoas livres, trabalhando em conjunto com os meios de produção realizados em comum. Todas as características do trabalho de Robinson Crusoe são repetidas aqui, mas com a diferença de que são sociais em vez de individuais. A produção total de associação é produto social, tanto na produção como na distribuição.

$16^{\circ}$ e $17^{\circ}$ parágrafos, p. 153- 154: Sociedade de mercadorias e religião 1) A sociedade dos produtores de mercadorias consiste em uma relação social de produção, ou seja, eles tratam seus produtos como mercadorias, portanto como valores, que é um "trabalho humano igual" ou trabalho abstrato.

2) As religiões mais apropriadas para o desenvolvimento burguês são a versão do cristianismo no protestantismo, por causa do culto religioso da 
pessoa em abstrato. A ideia de igualdade e liberdade das pessoas humanas surgiu com o cristianismo, que fundamentou essas categorias na comunidade.

$18^{\circ}$ parágrafo, p. 154: Economia Política e a categoria valor

1) A economia política descobriu a categoria valor, mas analisou o valor e a sua grandeza de forma incompleta. Nunca perguntou por que o trabalho é expresso em valor e por que a medida do trabalho é expressa na grandeza do valor do produto.

2) Para os economistas políticos, essas categorias parecem evidentes e a sua consciência burguesa não percebe que o processo de produção domina os seres humanos. Por isso eles entendem isso como uma necessidade natural evidente como o trabalho produtivo.

19 parágrafo, p. 154-156: Economistas clássicos e fetichismo

- Os economistas clássicos são enganados pelo fetichismo ligado a mercadoria e a aparência objetiva da determinação do valor dos produtos. Esse valor aparece como propriedade natural dos produtos do trabalho, ou seja, uma naturalização do produto social do trabalho.

$\mathbf{2 0}^{\circ}$ parágrafo, p. 157: A forma da mercadoria e seu fetiche 1) A forma da mercadoria é a forma mais geral e a menos desenvolvida da produção burguesa, no entanto, seu caráter fetichista ainda é fácil de penetrar. No entanto, quando chegamos a formas mais concretas, essa aparência de simplicidade desaparece.

2) Marx coloca muitas questões, por exemplo, de onde surgiram as ilusões do Sistema Monetário? Este não vê ouro e prata representando o dinheiro como uma relação social de produção, mas apenas como forma de objetos naturais.

$\mathbf{2 1}^{\circ}$ parágrafo, p. 157-158: Categorias e confusão dos economistas

1) A forma da mercadoria é um objeto de valor de uso, porque a mercadoria interessa as pessoas. O que pertence aos objetos é o valor e se torna um meio de valor de troca.

2) Marx ironiza os economistas através de um diálogo em que eles expressam a alma das mercadorias. 
$\mathbf{2 2}^{\mathbf{0}}$ parágrafo, p. 158: Valor de uso, Valor, Valor de troca

1) Os economistas pensavam ter descoberto que o valor de uso dos objetos fosse inerente aos próprios objetos. Ou seja, que o valor de uso das coisas se realizasse sem a troca, isto é, numa relação imediata entre coisas e seres humanos. No entanto, seu valor é realizado apenas na relação de troca, ou seja, em um processo social.

2) Marx critica esta teoria dos economistas, pois, o valor do uso apenas se realiza na relação do ser humano e o objeto. $\mathrm{O}$ valor faz parte dos objetos enquanto são o produto de um processo social de produção. Os economistas naturalizam o valor e com isso tornam a mercadoria infinita. Ora, isso é uma aparência falsa que surge na consciência dos economistas, pois eles defendem que a produção capitalista é a forma natural da produção. Por isso, costuma-se dizer, que o capitalismo é o fim da história, ou seja, o capitalismo não é uma totalidade finita, mas infinita. A teoria do fetichismo explicita, ao contrário, que a mercadoria é finita, embora os economistas construam o fetichismo da mercadoria como infinita.

A estruturação do texto de Marx sobre o fetichismo da mercadoria teve a finalidade de apresentar o conteúdo deste texto programático, pois ele sintetiza os desdobramentos de $O$ Capital. Nosso objetivo é focar apenas na análise dos cinco primeiros parágrafos como uma amostra da teoria do fetichismo.

\section{2 - Fetichismo da Mercadoria e suas oposições}

Oposição sensível x suprassensível: Marx começa descrevendo o fetichismo da mercadoria na sua imediatidade sensível como um produto do trabalho humano a fim de satisfazer suas necessidades básicas como um valor de uso. Porém, aqui surge uma primeira oposição entre a 'coisa sensível' que é útil ao ser humano e a 'coisa suprassensível'. Quando surge esta oposição? No momento em que o objeto é transformado em mercadoria. Marx fornece o exemplo da mesa que ao se tornar mercadoria ela transcende os sentidos, ou seja, torna-se algo metafísico (ver § 1). O fetichismo é descrito como algo cheio de "sutilezas metafísicas e melindres teológicos e misterioso”. O fetiche incorpora-se no objeto sensível que se torna, misteriosamente, um objeto suprassensível e eleva-se teologicamente como a deusa mercadoria. 
Oposição entre qualidade de trabalho x quantidade de tempo: as qualidades do trabalho implicam o dispêndio da força de trabalho humano. Esse trabalho torna-se abstrato, isto é, qualitativamente igual nas diferentes mercadorias. A qualidade do trabalho difere, apenas, na sua quantidade, pois, um trabalho é medido pela quantidade de tempo para produzir uma mercadoria. Então, a oposição entre qualidade e quantidade ocorre assim: a medida do trabalho pela quantidade de tempo pressupõe a redução da qualidade do trabalho através do dispêndio da força de trabalho humano no sentido fisiológico, isto é, o trabalho humano abstrato igual exteriorizado nas mercadorias (ver $\S 2$ ). O fetichismo torna-se místico, pois a mercadoria não é mais identificada em sua qualidade, mas ela aparece como valor de troca quantificado: igual trabalho humano abstrato. Na produção de mercadorias essa medida do trabalho aparece no valor e sua grandeza no produto. $\mathrm{O}$ trabalho abstrato quantificado tornase uma rede mística que une toda a realidade.

Oposição entre relação produtores $X$ relação mercadorias: $\mathrm{O}$ próximo nível da mercadoria é a esfera social. O trabalho humano imediato exterioriza-se em forma física em algum objeto. Essa força de trabalho exterioriza-se em algum produto que se torna mercadoria. A medida da quantidade de trabalho exteriorizado na mercadoria é quantificada para calcular o valor dos produtos do trabalho. Então, a relação entre os produtores passa a ser mediada pela relação com as mercadorias (ver § 3). O fetiche determina-se como enigma, pois, a mercadoria torna-se algo incompreensível ou ambíguo. Os produtores necessitam decifrar o enigma da mercadoria para compreender o oráculo proferido na relação com as mercadorias.

Contradição entre relação social dos produtores de mercadorias $X$ relação social entre as mercadorias: as oposições da forma mercadoria alcançam seu nível mais elevado na contradição entre os produtores e os produtos, entre o trabalho dos produtores e as mercadorias, entre sensível e suprassensível, entre sujeito e objeto. A mercadoria assume a forma de fantasma misterioso, isto é, uma imagem que aparece sob a forma de um objeto sensível que é a própria mercadoria (ver § 4). Ora, este é o fenômeno do fetichismo em que uma imagem se incorpora num objeto chamado mercadoria e ela passa a ter autonomia. Então, as mercadorias autônomas excluem-se umas às outras e excluem também os produtores de si. Eis o fetiche da mercadoria determinada em plenitude. As 
mercadorias passam a ter "vida própria", ou seja, são as deusas a quem os produtores devem reverência e subserviência. Este fenômeno do fetichismo é próprio "do mundo das mercadorias", isto é, surge historicamente na sociedade capitalista em que o trabalho social produz mercadorias (ver $\S 5$ ).

O fetichismo é, portanto, uma relação social entre pessoas mediada por coisas. O resultado é a aparência de uma relação direta entre as coisas e não entre as pessoas. As pessoas agem como coisas e as coisas como pessoas. O caráter enigmático do produto de trabalho provém da própria forma mercadoria. O misterioso da forma mercadoria consiste numa relação social existente fora deles, entre objetos. As mercadorias assumem uma relação externa aos seres humanos, passam a ter vida própria, tornam-se figuras autônomas, que mantém relações entre si e com os próprios seres humanos.

Reconstruímos a estrutura do texto sobre o fetichismo em O Capital I de Marx. Constatamos a conexão entre o fetichismo como fenômeno objetivo e subjetivo, como fato social objetivo e como fenômeno da consciência dos membros da sociedade burguesa. A reconstrução deste item é importante, porque ele contém em si, segundo Christian Iber, o todo da teoria marxiana.

Apresentamos também, acima, a teoria da infinitude de Hegel, a qual fundamenta o idealismo da filosofia e sua própria filosofia. Para Iber (2013), isto será útil a Marx, uma vez que o seu materialismo consiste em contestar que o finito se suprassume no infinito e que a contradição encontre sua reconciliação no infinito. $O$ finito permanece uma contradição que não se dissolve. O "perecer do perecer" é uma ilusão idealista, dirá Marx, pois o finito não se suprassume no infinito. Com Feuerbach, Marx diz: o finito tem uma natureza que não pode ser suprassumida. A idealidade do finito, que Hegel alveja, é apenas um aspecto, não o todo do finito.

A questão é, para Christian Iber, a seguinte: há também em Hegel um fetichismo, sobretudo, em sua Lógica? Marx opina que sim, pois, Hegel tornaria o pensar sujeito sob o nome da ideia que age na lógica e no mundo. Porém, o fundamento desse fetichismo dos pensamentos é diferente entre os dois: em Marx o fundamento do fetichismo é a mediação objetiva das relações sociais através de coisas, isto é, trata-se de uma naturalização das relações sociais. Enquanto que em Hegel - segundo 
Marx - o fundamento do fetichismo dos pensamentos é a transformação do pensar em um sujeito autônomo como ideia. Então, não é o ser humano que pensa, mas é a ideia lógica no ser humano que pensa. Trata-se de uma transformação metafísica do pensar, ou seja, o pensar é transformado em um fundamento metafísico. Em síntese, para Iber, o fetichismo em Marx é um fetichismo social - a dominação social entre pessoas aparece necessariamente como dominação de coisas sobre as pessoas. Enquanto que o fetichismo em Hegel é um fetichismo do pensar que está fundamentado na autoalienação metafísica do pensar humano (ver Iber, 2013).

\section{3 - Contradição que move o mundo: finitude $x$ infinitude}

\section{1 - Finitude das mercadorias e do fetiche infinito}

Tanto para Hegel quanto para Marx, as coisas enquanto tais são finitas. Marx entende, porém, que as coisas finitas não podem ser suprassumidas na infinitude. Nós temos que viver e lidar com a contradição das coisas finitas. Essa contradição não pode ser dissolvida, ou seja, essa negatividade não é suprassumível. Segundo Christian Iber, Hegel defende a soberania do pensar infinito sobre o mundo, enquanto Marx entende, de um lado, que a relação do pensar infinito com o mundo é, apenas, um aspecto do ser humano; de outro, a relação prática com o mundo é pensável, mas não suprassumível pelo pensar.

Os defensores do capitalismo, segundo Iber, afirmam que apenas como mercadorias as coisas podem desempenhar um papel econômico, ou seja, apenas uma economia monetária é racional. Isso é a infinitização das coisas finitas como mercadorias. A produção de bens será sempre o infinito produzir de mercadorias. Marx dirá que isso é uma ideologia, pois, as coisas enquanto tais podem ser utilizadas como objetos econômicos, isto é, as coisas finitas podem ser organizadas racionalmente como objetos econômicos. As coisas não precisam se afirmar como mercadorias, assim como ocorre no capitalismo. Planejamento racional da produção e da distribuição das coisas finitas para a satisfação das necessidades humanas, ao invés da concorrência pelo dinheiro, isso seria um materialismo racional na teoria e na prática econômica e política. Tomemos as coisas finitas e nossos projetos nas nossas próprias mãos, afirma Iber. 
Marx decifra o fetichismo da mercadoria explicando que a produção das mercadorias não é um fenômeno social eterno e infinito, mas finito, isto é, histórica e socialmente determinado. Para Iber, o capitalismo não é o fim da história, mas apenas o fim da história natural. A teoria marxiana revela o capitalismo como uma totalidade finita, historicamente determinada e abre, com isso, um horizonte para uma nova sociedade mais humana no futuro.

O idealismo hegeliano é o idealismo absoluto como unidade do idealismo e do realismo. O materialismo marxiano é um idealismo sem absoluto, um materialismo com a unidade do realismo e do idealismo, conclui Iber.

\section{2 - Da finitude à infinitude, do abstrato ao concreto}

Apresentamos, agora, o ponto de vista de Hegel face à crítica de Marx de que o pensamento lógico é a autoalienação metafísica do pensar humano, isto é, a resposta à crítica de Marx ao idealismo. A resposta hegeliana, afirma Federico Orsini, defende a neutralização da oposição entre realismo e idealismo, que Marx continua mantendo como válida. Acusar Hegel de hipostasiar o pensamento humano equivale a fazer a pressuposição de que o pensamento seja um predicado, exclusivamente, humano, mas é justamente essa ideia da filosofia moderna que Hegel está criticando, afirma Orsini. ${ }^{5}$

Reconstruímos, brevemente, o texto de Orsini que tem por base as teses de Roberto Fineschi (2006) em três pontos: a interpretação marxiana de Hegel, sua origem e pertinência.

a) Hegel segundo Marx: Para Marx, Hegel transforma o processo real em um processo da autoconsciência em que a subjetividade humana absorve no puro pensar a objetividade. Ou seja, o pensar é o sujeito que torna o real mero predicado em que a matéria está destinada a ser suprassumida pela autoconsciência, reconhecendo o real como produto da própria exteriorização. Esta é a posição do jovem Marx exposta nos Manuscritos de 1844 e usada na Sagrada Família (1845). Em outras

\footnotetext{
${ }^{5}$ Federico Orsini. Contribuição para uma relação crítica entre Hegel e Marx. Seminário sobre Leitura de O Capital de Marx 2016/o1. Porto Alegre: PPG Filosofia PUCRS, 07.03.2016. Nesse texto, Orsini, escreve sobre a relação Hegel-Marx, baseando-se, especialmente, nas teses do texto de Roberto Fineschi 'Hegel e Marx" de 2006.
} 
palavras, ele qualifica a filosofia hegeliana como a filosofia da autoconsciência em que o Eu absoluto "cria 'mentalmente' o mundo, formando um ciclo de alienação e retorno para si a partir da alienação" (Orsini, 2016, p. 2).

Essa leitura marxiana permanecerá ao longo de sua vida, porém, há uma diferença entre o jovem Marx e o maduro, que a partir de 1857 constrói o modelo teórico para $O$ Capital. Enquanto o jovem Marx qualifica o método da descida do abstrato para o concreto como sendo algo metafísico ou místico, o Marx maduro considera apropriado tal procedimento em que o método científico recria e reproduz o real no pensamento. Essa mudança na compreensão da relação entre abstrato e concreto que reconhece o mérito hegeliano em detrimento de Feuerbach, não modifica de modo geral a leitura marxiana de Hegel, que é o da esquerda hegeliana, afirma Orsini.

b) Marx e a esquerda hegeliana: Marx lê os textos de Hegel, sobretudo, a Filosofia do Direito e o capítulo final da Fenomenologia do Espírito, a partir da esquerda hegeliana (Feuerbach, Bruno Bauer, etc.). Porém, o Marx maduro reavalia, de um lado, sua posição, afastando-se da tese da inversão sujeito-predicado (Feuerbach), de outro, permanece uma visão de fundo que considera Hegel um místico-neoplatônico em que o universo material é uma emanação do pensamento imaterial. Marx reconhece o valor do método dialético, porém, esse método é usado para construir um sistema místico em que o pensar cria a realidade material através do conceito. Daqui surge a oposição materialismo x idealismo que se prolongará nos textos de Marx e Engels. Essa oposição "equivale a afirmar que a reconstrução conceitual (ou 'ciência') não cria, mas recria um concreto que, como tal, em sua materialidade, preexiste a sua formulação conceitual" (ORSINI, 2016, p. 3).

c) Do concreto ao abstrato (Da finitude à infinitude: investigação), do abstrato ao concreto (Da infinitude à finitude: apresentação): a oposição idealismo e materialismo precisa ser bem entendida, pois, afirmar que a matéria preexiste ao pensar e não vice-versa, baseia-se na identificação acrítica do pensar (ideia) com o material (real). Pois, a chamada inversão dialética do Marx d'O Capital, não confere primazia do conhecimento sensível do finito sobre o pensar como infinito, mas compreende o duplo movimento do método: a subida do concreto para o abstrato, e depois, da descida do abstrato para o concreto. Ou seja, Marx começa com a análise 
conceitual do material empírico histórico elaborado pelos economistas clássicos da mercadoria como célula econômica (método da investigação), para depois, apresentar a dialética da mercadoria através dos conceitos em O Capital (método da apresentação).

Então, não há uma inversão da dialética hegeliana, mas o uso da mesma para analisar a mercadoria, pois para Hegel, "o conhecimento produz o real, mas não no sentido de criar a materialidade dele” (p. 4). A Filosofia reconstrói de forma conceitual o material empírico e a representação objetiva. Por isso, “tanto a 'inversão' do método quanto o 'materialismo' reivindicados por Marx são, de fato, pseudo questões, a saber, questões que surgem unicamente de sua recepção de Hegel, recepção que hoje aparece como uma imposição desconectada da interpretação rigorosa dos textos hegelianos” (p. 4).

À medida que Marx avança na elaboração da teoria do sistema de produção capitalista, observa Orsini, ele se afasta do jovem hegeliano, para se tornar um pensador dialético. Marx elabora a teoria do processo histórico que se diferencia daquela hegeliana, não por causa do problema idealismo e materialismo, mas pela definição de quais seriam os sujeitos e as formas desse processo. Enfim, uma abordagem proveitosa da relação entre Hegel e Marx exige tomar o caminho do método dialético, abandonando "a ótica da autocompreensão marxiana de sua relação com Hegel” (p. 5), proveniente de sua fase juvenil.

\section{Referências}

BELLOFIORE, R. "Lost in Translation: Once Again on the Marx-Hegel Connection", In: "Marx's Capital and Hegel's Logic", pp 164-188, 2014.

FINESCHI, Roberto. Marx e Hegel. Contributi a una rilettura. Roma: Carocci, 2006.

HEGEL, G. W. F. Ciência da lógica. A Doutrina do Ser (1832). Trad. Christian G. Iber et alii. Petrópolis: Editora Vozes, 2016.

IBER, Christian. Elementos da teoria marxiana do capitalismo. Um comentário sobre o livro I de O Capital de Karl Marx. Porto Alegre: Editora Fi/EDIPUCRS, 2013.

MARX, Karl. O Capital: crítica da economia política. Livro I: O processo de produção do capital. Trad. Rubens Enderle. São Paulo: Boitempo, 2013. 
A. Bavaresco - Idealismo Realista ou Realismo Idealista: Hegel \& Marx | 375

ORSINI, Federico. Contribuição para uma relação crítica entre Hegel e Marx. Seminário sobre Leitura de O Capital de Marx 2016/o1. Porto Alegre: PPG Filosofia PUCRS, 07.03.2016.

ORSINI, Federico. Passagem. Observação 2: O Idealismo. Material usado em Seminário Doutrina do Ser de Hegel, Porto Alegre: PUCRS, dia 05.06.2017, p. 3-4.

\section{Endereço postal}

Programa de Pós-graduação em Filosofia da PUCRS

Av. Ipiranga 6681, prédio 9, Porto Alegre, RS, Brasil

Data de recebimento: 29/01/2018

Data de aceite: 11/03/2018 